\title{
PERSEPSI MASYARAKAT TERHADAP TINGKAT KENYAMANAN VISUAL PERMUKIMAN NELAYAN STUDI KASUS: PEMUKIMAN NELAYAN LETTE
}

\begin{abstract}
Nurmiah
Abstrak

Pemukiman nelayan adalah suatu pemukiman bagi masyarakat secara visual, dipandang kumuh dan kawasan tertinggal yang tidak memenuhi persyaratan ideal suatu hunian secara tekhniks maupun non tekhnis. Hal itu mendorong pemerintah untuk merivatilisasi kawasan itu dengan pengadaan dan pembenahan infrastruktur yang ada Kota Makassar juga terkenal sebagai kota bahari yang memiliki banyak potensi namun mengalami problema yang terjadi diatas. Dalam revitalisasi kawasan Lette yang diadakan pemerintah tidak membuat efek keindahan bagi kawasan tersebut namun, yang terjadi adalah kawasan Lette kembali menjadi kawasan yang kumuh. Salah satu penyebabnya kawasan Lette kembali menjadi kawasan kumuh, adalah pembenahan yang dilakukan pemerintah belum sesuai dengan apa yang dipersepsikan sehingga menimbulkan berkurangnya apresiasi masyarakat untuk tetap menjaga lingkunganya.Penelitian ini bertujuan untuk meningkatkan kenyamanan visual dikawasan Lette. Kenyamanan visual di kawasan Lette dapat kita ukur dengan mengetahui bentuk persepsi masyarakat dan apa yang menjadi faktor utama pembentuk persepsi visual mereka. Sehingga acuan ini dapat menjadi tahap peningkatan kenyamanan visual kawasan Lette dari tingkat kumuh. Landasan teori dari penelitian ini adalah bagaimana mengarahkan persepsi masyarakat tentang kenyamanan visual pada standart desain suatu waterfont yang ideal, dan juga mengarahkan persepsi masyarakat Lette pada faktor - faktor pembentuk kenyamanan visual tata massa bangunan, ruang, sirkulasi, vegetasi, street forniture, fungsi aktifitas. Untuk mengarahkan perancangan pada faktor - faktor visual yang secara kuantitas menpengaruhi kenyamanan visual. Metode yang dipakai penelitian ini adalah metode kuantitatif dengan pendekatan rasionalistik, dengan cara wawancara, observasi, dan suvey. Hasil dari penelitian ini diharapkan dapat dijadikan suatu patokan untuk mengatasi permasalahan kenyamanan visual pada kawasan nelayan.sehiingga pemerintah mendapatkan suatu langkah yang tepat guna.
\end{abstract}

Kata kunci: kawasan pemukiman nelayan, kenyamanan visual, persepsi.

\begin{abstract}
Fishermen settlement area in actual fact is a settlement area for the society. However it is visually regarded as slum as well as poor which does not meet the requirement of reasonable settlement both in technical and non technical aspect. This has given birth to its revitalization by the government by fixing and developing the infrastructures. Makassar is a maritime city which possesses a lot of natural resources and potential, despite the fact that it also has to deal with the aforementioned problem. By government's revitalization in Lette Area, in reality has failed to bring comfort and attractive senses to the community. Even, it goes back to be a slum area.

One of the cause why it becomes slum again is the government's revitalization does not in line with the residents' perception. This is really ineffective as it fails to satisfy the community's expectation in activities, infrastructures management, cultures and so on. Thus it encourages the declining of their appreciation and support in protecting their own environment.

This study aims at raising the visual comfort of in Lette Community through examining the forms of perceptions as well as the dominant factors contributing to the perceptions development. This result can be functioned then as a reference of the efforts of the visual comfort development of Lette Community. The theoretical framework is how to direct the community's perception to visual comfort in the ideal of waterfront standard design. Also, how to direct their perceptions on the factors of the perceptions' development such as building massa design, spaces, circulation, vegetation, street furniture and activity functions. The method used in the research is quantitative with rasionalistic approach which is conducted by interview, observation and survey.

Definitely, the results of the study can be expected as a reference as well as model in how to deal with the condition of discomfort or slum of a fishermen neighborhood according to visual perceptions and expectations of the community which is in turn, will support the effectiveness of government's initiatives in dealing with the problem..
\end{abstract}

Keywords: fisherman settlement area, perseption, visual comfort 


\section{PENDAHULUAN}

Lokus penelitian ini berfokus pada kawasan pemukiman nelayan Lette - Makassar, yang posisinya berada di kawasan kota pantai. Secara administratif, Makassar merupakan Ibukota Sulawesi Selatan, yang terletak di pusat propinsi Sulawesi selatan.Makassar terdiri dari 14 kecamatan, luasan seluruh kecamatan 1.595,57 km2 dan khususnya kecamatan Mariso mempunyai 9 kelurahan dengan luasan 1,82 km2. Kawasan Lette adalah pemukiman nelayan secara visual dinilai kumuh. Kondisi kawasan Lette sangat kontras dengan pantai Losari yang tertata rapih dan bersih. Pantai Losari terletak di bagian utara Lette dan terkenal sebagai salah satu landmark kota Makassar. pembenahan kawasan Lette berfokus di pengadaan rumah susun dan infrastruktur. Upaya dari pemerintah tersebut tidak menyelesaikan masalah, terutama tentang ketidakserasian antara perilaku dengan lingkungannya. Hal ini menimbulkan efek ketidaknyamanan visual. Bagaimana bentuk persepsi visual masyarakat Lette yang mayoritasnya sebagai nelayan? sehingga tujuan dari penulisan jurnal ini dengan mempelajari bentuk persepsi masyarakat pemukiman nelayan Lette terhadap kenyamanan visual lingkungan. Sehinggan nantinya dapat merumuskan arahan desain, terkait aspek kenyamanan visual lingkungan pemukiman nelayan Lette.

Lokasi penelitian ini berada di daerah Makassar lokasi khususnya berada di pemukiman nelayan kampung Lette Makassar daerah amatanya meliputi 9 kelurahan dan daerah penelitian meliputi kawasan kampung nelayan lette Makassar dengan luas kawasan $1,82 \mathrm{~km}^{2}$

\section{ISI PENELITIAN}

\subsection{Metode}

Pada penelitian ini menggunakan metode kuantitatif dengan pendekatan rasionalistik melalui penekanan pada makna empiris yaitu realitas dikorelasikan dengan teori yang relevan dengan objektifitas kawasan penelitian, sehingga menggambarkan hasil rekonstruksi fenomena, dalam hal ini pemukiman nelayan Lette Makassar. Pemilihan data ini ditekankan pada indicator yang memiliki keunikan yang memudahkan kategorisasi. Untuk memperdalam pembahasan spasial dilakukan juga observasi dibeberapa kasus spasial khusus berupa wawancara sejumlah responden yang tinggal dilokus penelitian untuk melihat persepsi mereka terhadap kawasan.

\subsection{Hasil}

Hasil penelitian dijabarkan pada tabel 1dibawah ini
Tabel 1. Presentasi Persepsi

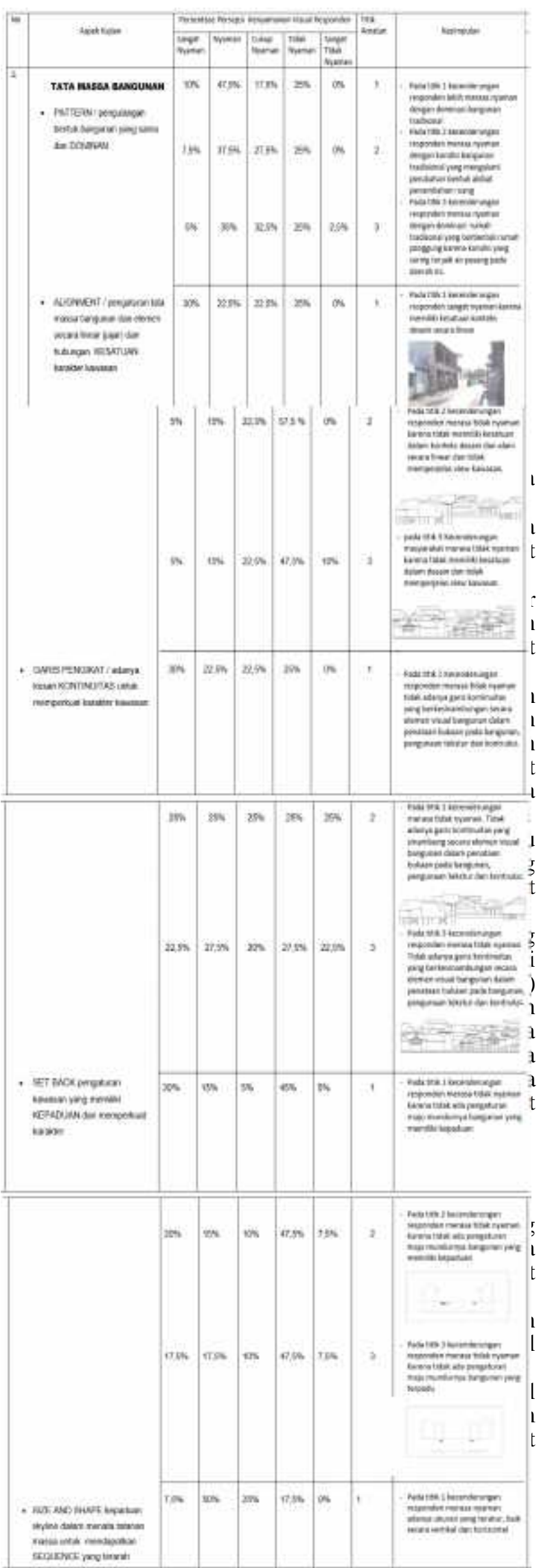




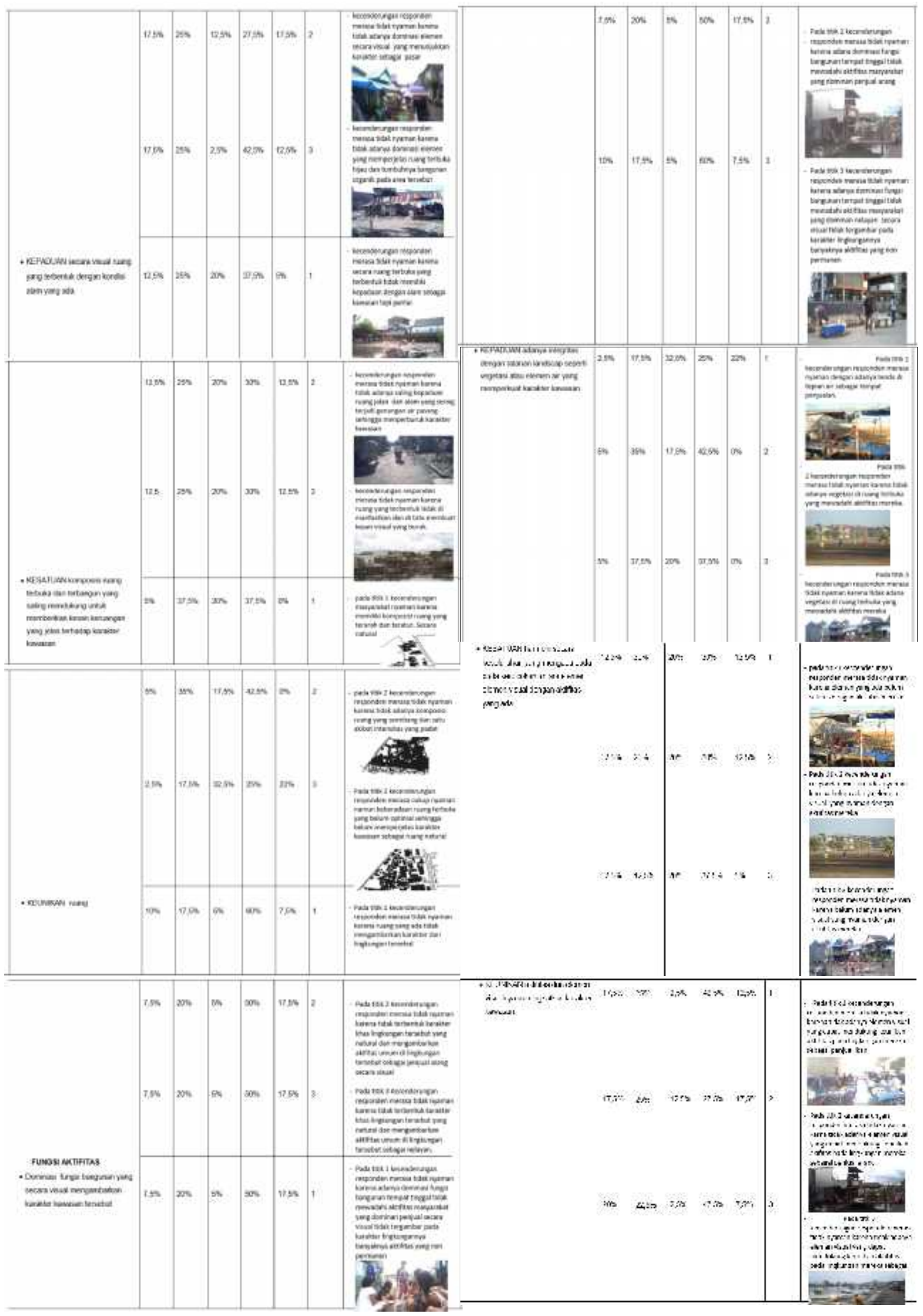




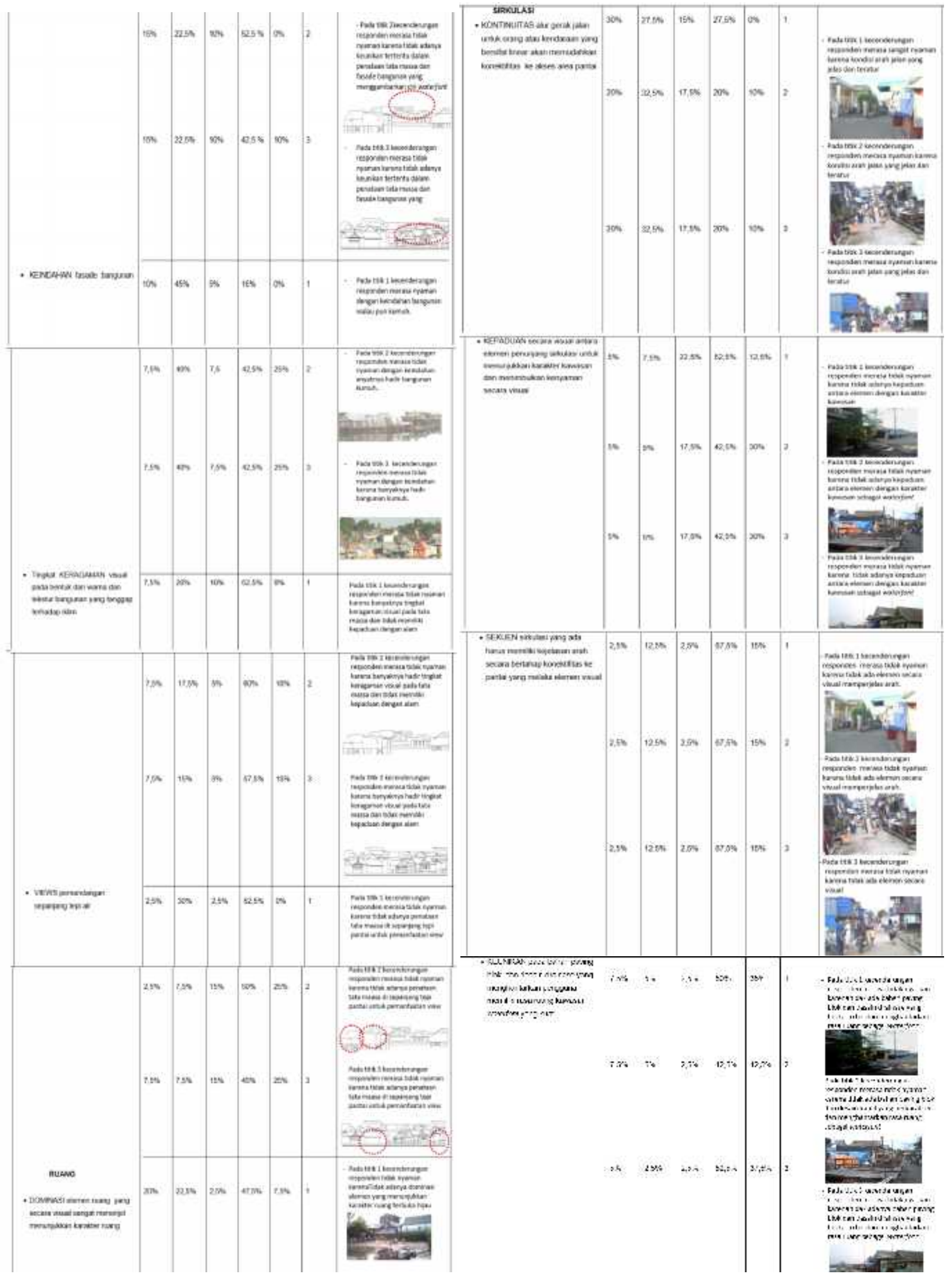




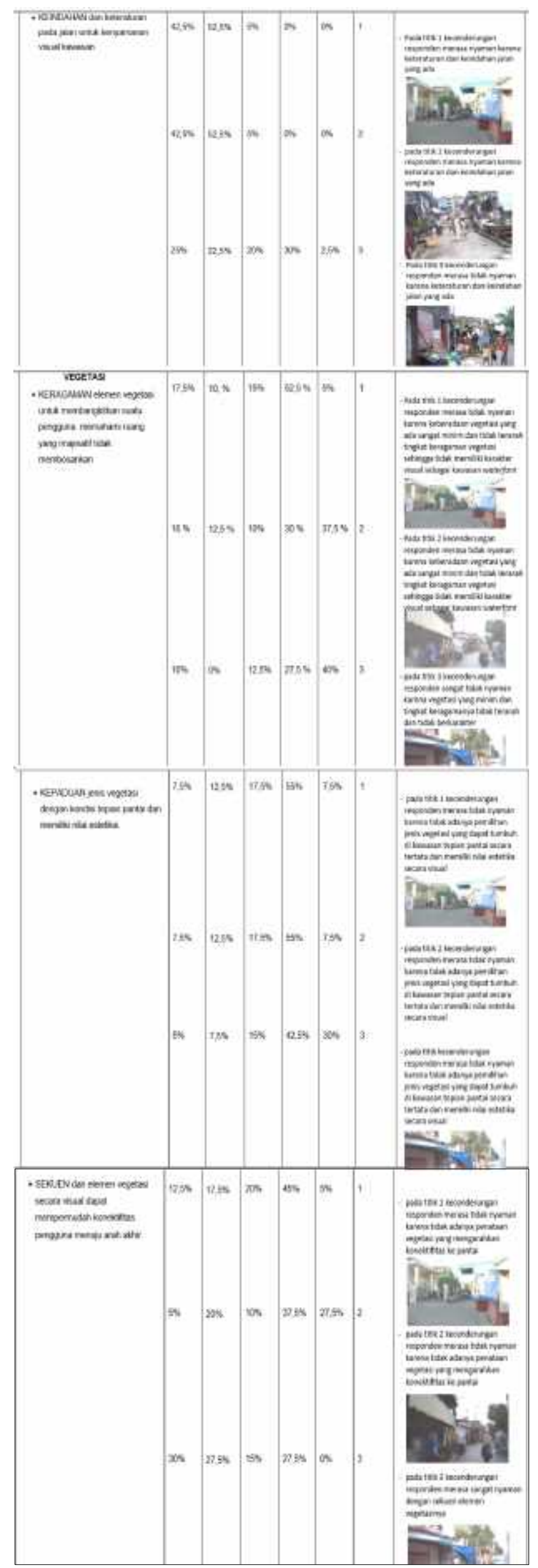

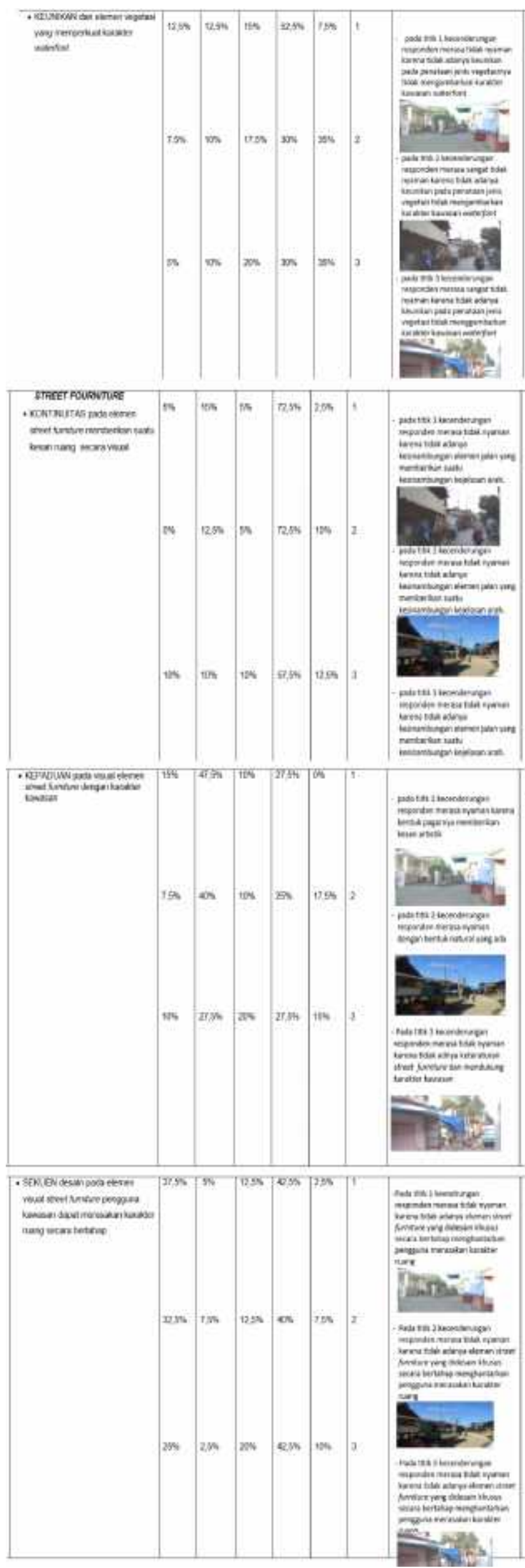



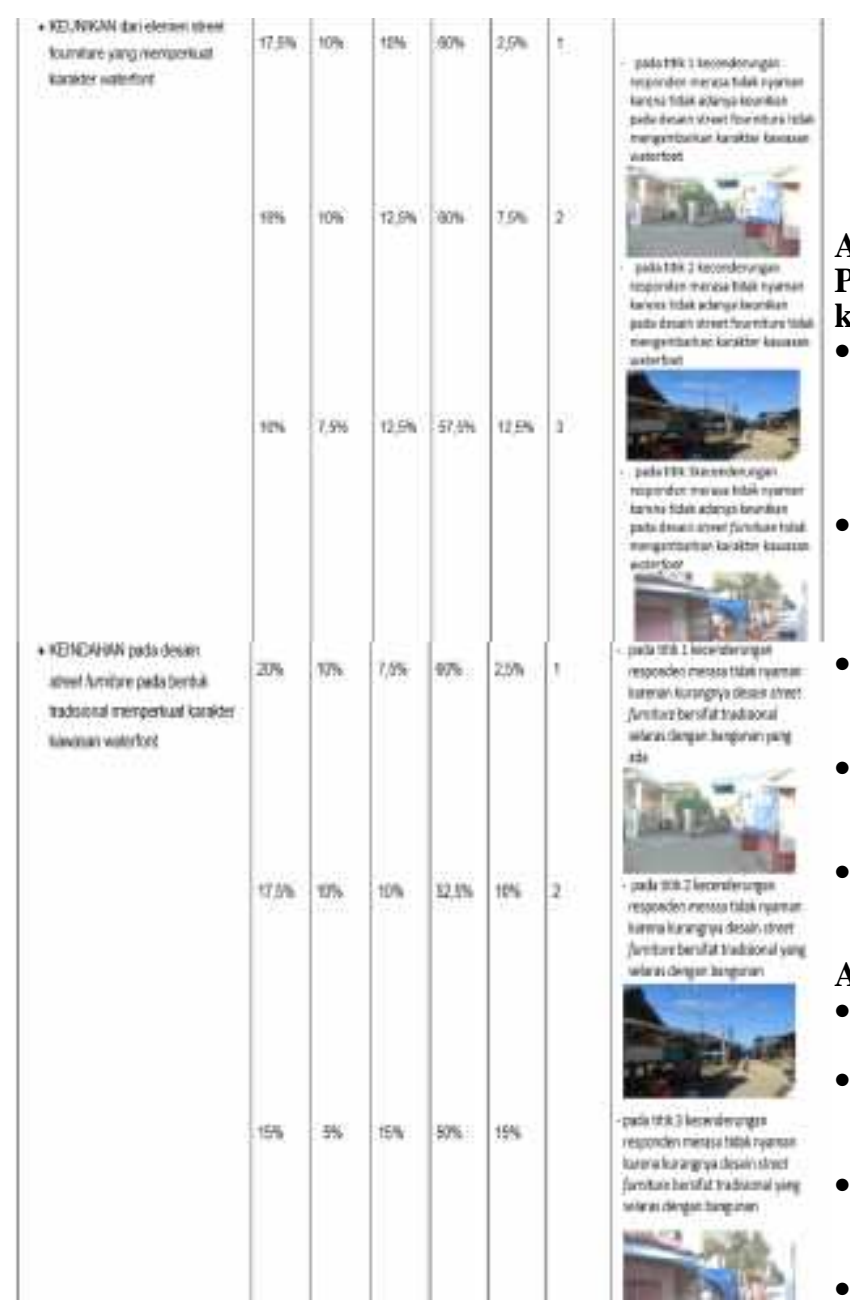

\subsection{Pembahasan}

Persepsi kenyamanan visual sirkulasi

- Adanya kontuinitas alur gerak dan kondisi arah jalan yang jelas dan teratur membuat kenyamanan visual,.

- Adanya kepaduan antara elemen visual sirkulasi dengan karakter kawasan sebagai waterfont membuat kenyamanan visual

- Elemen secara visual menperjelas arah menperjelas sequen membuat kenyamanan visual.

- Desain bahan paving blok dan desain kanal yang berkarakter dan menhantarkan rasa ruang dan memiliki keunikan tersendiri sebagai kawasan waterfont merasa nyaman karena keteraturan dan keindahan jalan yang ada membuat kenyamanan visual.

- Adanya kepaduan antara elemen visual sirkulasi dengan karakter kawasan sebagai waterfont membuat kenyamanan visual.

- Elemen secara visual menperjelas arah menperjelas sequen membuat kenyamanan visual.

- Desain paving blok dan desain kanal yang berkarakter dan menhantarkan rasa ruang dan memiliki keunikan tersendiri sebagai kawasan waterfont membuat kenyamanan visual.

- Keindahan jalan yang didesai melalui elemen visual yang ada membuat kenyamanan visual

\section{A.4 vegetasi}

Persepsi kenyamanan visual vegetasi pada titik krusial 1

- Vegetasi yang minim dan tingkat keragamanya tidak terarah dan tidak berkarakter sehingga kurang meniptakan ruang yang imajinatif membuat ketidaknyamanan visual.

- Pemilihan jenis vegetasi yang dapat tumbuh di kawasan tepian pantai secara tertata dan memilki nilai estetika membuat kenyamanan secara visual.

- Penataan elemen visual vegetasi menbentuk sekuen pada suatu kawasan membuat kenyamanan visual

- Desain elemen vegetasi yang mengambarkan keunikan karakter kawasan waterfont membuat kenyamanan secara visual

- Desain elemen vegetasi yang mengambarkan keunikan pada karakter kawasan waterfont membuat kenyamanan secara visual.

\section{A.5 Street Forniture}

- Persepsi kenyamanan visual street furniture pada titik krusial 1.

- Adanya kesinambungan elemen jalan yang memberikan suatu kejelasan arah membuat kenyamanan visual.

- Adanya kepaduan street furniture yang mendukung karakter kawasan membuat kenyamanan secara visual.

- Adanya elemen street furniture yang didesain khusus secara bertahap menhantarkan pengguna merasakan karakter ruang membuat kenyamanan secara visual

- Adanya keunikan pada desain street furniture tidak mengambarkan karakter kawasan waterfont membuat kenyamanan visual

\section{B. Arahan Desain}

\section{B.1 Tata Massa Bangunan}

Fasade bangunan berkembang belum sesuai dengan konteks kawasan Lette sebagai kawasan waterfont, perulangan pasade bangunan selain perulangan bentuk, dimensi dan jarak antara bangunan, set back terbentuk dari rasio perbandingan ketinggian dan jarak juga bangunan, allingment terbentuk oleh ketinggian bangunan, size dan shape terbentuk dari ukuran yang sama dan similarity yang terbentuk dari kemiripan bentuk menpunyai pengaruh terhadap karakter penampilan, yang kebanyakan dari persepsi masyarakat Lette penampilan bangunan yang nyaman bila menpunyai style tradisional dan tidak berkesan kaku dan monoton pada perulanganya itu bisa di imbangi dari memberi regulasi hirarki kawasan dari awal memasuki kawasan hingga ke pusat kawasan. 


\section{B.2 Pattern}

Selain pengulangan bentuk tradisional yang harus dipertahankan dengan ukuran jarak 5 meter juga mempunyai pengaruh terhadap karakter penampilan bangunan dan penggunaan jenis material dan ornament tradisional yang mendukung karakter kawasan.

\section{B.3 Aligment}

Mempertahankan alignment secara horizontal yang terbentuk oleh ketinggian bangunan, untuk memperkuat karakter visual dengan pembentukan ornament yang berulang dan segaris.

\section{B.4 Size and Shape}

Untuk memperkuat karakter visual bangunan mempertahankan karakter bangunan melalui ketinggian bangunan melalui ornamen yang berkarakter pada atap bangunan tradional.

\section{B.5 Street Furniture}

Untuk kenyamanan penggunaan ruang public perlu didukung oleh keberadaan elemen seperti tempat duduk, vegetasi, tempat parker. Untuk street furniture yang berada di ruang jalan perletakannya tidak dibahu jalan dan diatas jalur pedestrian yang mengurangi kenyamanan pengguna jalan lainnya. Untuk memperkuat kualitas visual suatu kawasan dan ciri kawasan diperlukan desain yang kontekstual dengan kawasan. Desain street furniture yang bermotif tradisional dan natural yang konteks dengan karakter kawasan akan memperkuat kualitas visual kawasan.

\section{B.6 Vegetasi}

Vegetasi yang ada pada kawasan Lette yang minim menjadikan berkurangnya kenyamanan visual pada kawasan Lette. Pada jenis vegetasi dapat direkomendasikan jenis vegetasi yang sesuai persepsi kenyamanan visual masyarakat yaitu vegetasi berjenis bulat dan lebat yang dapat tumbuh di daerah pinggiran pantai, seperti akasia. Hal itu dapat disesuaikan dengan jenis vegetasi yang dapat tumbuh dikawasan waterfront seperti kelapa dan palem.

\section{B.7 Ruang}

Untuk mengantisipasi kerapatan bangunan dan menjaga adanya jarak antara bangunan, perlunya acuan yang mengatur penambahan bangunan. Desain ruang terbuka pada kenyamanan visual yang berkonsep green.

\section{KESIMPULAN}

Faktor-faktor penentu untuk meningkatkan kenyamanan visual pada suatu kawasan apabila menperhatikan apa yang menjadi persepsi masyarakat pada karakter-karakter visual kawasan tersebut. Seiring dengan perkembangan yang ada menyebabkan persepsi setiap orang pada suatu kawasanpun bertambah. Sehingga pertumbuhan dan penataan suatu kawasan menuntut kita pada suatu bentuk mencari titik temu antara persepsi masyarakat dengan suatu standar perancangan visual yang ada sehingga apresiasi masyarakat pada suatu kawasan Unsur kualitas visual apa yang paling berperan menbentuk kenyamanan visual an semakin meningkat.

- Penataan bentuk bangunan yang sama yang berciri tradisional sehingga masyarakat merasakan kenyaman secara visual

- Pengaturan pola tata massa secara linear yang memiliki kesatuan.konteks dengan desain dan alam sehingga masyarakat merasakan kenyaman secara visual

- Dominasi elemen yang menperjelas ruang terbuka hijau dan penataan tumbuhnya bangunan organik pada area tersebut membuat kenyamanan secara visual

- Keberadaan ruang terbuka yang sesuai dengan karakter kawasan sebagai ruang natural membuat kenyamanan visual

- Terbentuk karakter ruang yang natural yang mewadahi aktivitas umum dilingkungan tersebut sebagai nelayan membuat kenyamanan visual.

- Adanya kontuinitas alur gerak dan kondisi arah jalan yang jelas dan teratur membuat kenyamanan visual

- Adanya kepaduan antara elemen visual sirkulasi dengan karakter kawasan sebagai waterfont membuat kenyamanan visual

- Elemen secara visual menperjelas arah menperjelas sequen membuat kenyamanan visual

\section{DAFTAR PUSTAKA}

[1] Agung Nugroho, Ari , 2009 ,Study Persepsi Visual Sebagai Dasar Penataan Komposisi Papan Reklame Lepas Dijalan Simpang Empat. Jutap Pasca Sarjana UGM, Yokyakarta

[2] Breen and Rigby, 1996, The New Water Font, Mc. Graw-Hill

[3] Cullen ,G. 1961. . The Architectural Press. London

[4] Dian, Damayanti, 2005 Peran Kualitas Visual Dalam Menentukan Karakter Kawasan Borobudur. Jutap Pasca Sarjana UGM, Yokyakarta

[5] Gostling , D . 1984. Pengantar Perancangan Kota, Erlangga, Jakarta

[6] Hakim R , 1993 Unsur - Unsur Perancangan Dalam Arsitektur , Bumi Aksara. Jakarta

[7] Rapoport, Amost, 1977, Human Aspect Of Urban Form, Pergamon Press, New York 